\title{
Constitutive nitric oxide synthase (cNOS) activity in Langerhans islets from streptozotocin diabetic rats
}

T.M. Fonovich de Schroeder,
M.D. Carattino, M. Frontera
and O.L. Catanzaro
Facultad de Farmacia y Bioquímica, Cátedra de Fisiología, PROSIVAD-CONICET, Universidad de Buenos Aires,

Buenos Aires, Argentina
Correspondence

T.M. Fonovich de Schroeder Facultad de Farmacia y Bioquímica Cátedra de Fisiología, PROSIVAD

Universidad de Buenos Aires Junín 956, Piso 7

1113 Buenos Aires

Argentina

Fax: 541-964-0667 or 541-767-5675

Research supported by CONICET

(No. 451).

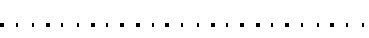

Received May 14, 1997

Accepted February 13, 1998

\section{Abstract}

Nitric oxide synthase activity was measured in Langerhans islets isolated from control and streptozotocin diabetic rats. The activity of the enzyme was linear up to $150 \mu \mathrm{g}$ of protein from control rats and was optimal at $0.1 \mu \mathrm{M}$ calcium, when it was measured after $45 \mathrm{~min}$ of incubation at $37^{\circ} \mathrm{C}$ in the presence of $200 \mu \mathrm{M}$ arginine. Specific activity of the enzyme was $25 \times 10^{-4} \mathrm{nmol}\left[{ }^{3} \mathrm{H}\right]$ citrulline $45 \mathrm{~min}^{-1} \mathrm{mg}$ protein $^{-1}$. Streptozotocin diabetic rats exhibited less enzyme activity both in total pancreas homogenate and in isolated Langerhans islets when compared to control animals. Nitric oxide synthase activity measured in control and diabetic rats 15 days after the last streptozotocin injection in the second group of animals corresponded only to a constitutive enzyme since it was not inhibited by aminoguanidine in any of the mentioned groups. Hyperglycemia in diabetic rats may be the consequence of impaired insulin release caused at least in part by reduced positive modulation mediated by constitutive nitric oxide synthase activity, which was dramatically reduced in islets severely damaged after streptozotocin treatment.

\section{Introduction}

Nitric oxide synthase (NOS) activity has been detected in insulin-producing cells (13 ). As in other tissues, a constitutive and an inducible form of the enzyme were described in Langerhans islets. The inducible form appears to be responsible in part for $\beta$-cell destruction in insulin-dependent diabetes mellitus (IDDM) through the production of large amounts of nitric oxide (NO). Macrophages and monocytes infiltrate the islets early during insulitis, with the later appearance of T-lymphocytes. The immune response begins with macrophage release of cytokines, such as interleukin 1 (IL-1), interferon $\gamma$
Key words

- Nitric oxide synthase

- Nitric oxide

- Langerhans islets

- Streptozotocin

- Diabetes
(IFN- $\gamma$ ) and tumor necrosis factor (TNF). These effectors mediate inducible NOS (iNOS) induction in BB rats and NOD mice (1). At least two or three cytokines are required for iNOS activation in human pancreatic islets (2). Flodström et al. (3) have demonstrated that cytokines activate nuclear transcription factor $(\mathrm{NF}-\mathrm{\kappa B})$ in primary adult human pancreatic islets and that this activation is necessary for cytokine-induced iNOS expression. B-cell destruction in autoimmune diabetes (IDDM) is a T-lymphocyte-dependent process, although NO released from Bcells and macrophages has been recently proposed to be an effector molecule that also participates in $\beta$-cells damage $(1,4-6)$. 
Reaction of NO with superoxide anion produces peroxinitrite, which rapidly decomposes to nitrogen dioxide and hydroxyl radical, both implicated in macrophage-mediated cytotoxicity (1). Metal- and thiol-containing proteins are major target sites for $\mathrm{NO}$, the molecule responsible for nitrosation reactions at nucleophilic centers (7). A variety of heme-containing proteins are under NO control. This compound is known to activate guanylate cyclase (a heme-containing enzyme) and the cyclic GMP (cGMP) thus produced is thought to be a second messenger in signal transduction mediated by NO $(8,9)$. Although IL-1 induces accumulation of cGMP by rat islets in a timedependent manner that mimics its time-dependent inhibition of insulin secretion, Corbett et al. (1) obtained substantial evidence against cGMP participation in the deleterious effects of IL-1 on islet function.

Endothelial NOS (eNOS) and neuronal NOS (nNOS) were described in different tissues and are collectively referred to as constitutive nitric oxide synthase (cNOS), because these isoforms are constitutively expressed (1). The constitutive isoform of pancreatic NOS (cNOS) was originally proposed to mediate glucose-stimulated insulin secretion under physiological conditions, but there is still little and controversial information about this possible role of cNOS. Schmidt et al. (9) found that L-arginine in the presence of D-glucose induces concomitant release of insulin and NO. In addition, the concentration of L-arginine that potentiates glucose-induced insulin release is in the physiological range. More recently Laffranchi et al. (10) postulated that NO can stimulate insulin secretion by deenergizing mitochondria, thereby triggering mitochondrial calcium release. On the other hand, Panagiotidis et al. (11) suggested that NO is a negative modulator of insulin release induced by L-arginine and glucose and that this effect may probably be the consequence of S-nitrosylation of critical thiol groups involved in the secretory process. Jones et al. (12) suggested that NO may be involved in long-term glucose-dependent increases in cGMP content of islet cells. These authors also reported that they found no evidence that $\mathrm{NO}$ generation is required for the initiation of insulin secretion. Pueyo et al. (13) evaluated the insulin response to several secretagogues in rats in which NOS was chronically inhibited by oral administration of $\mathrm{N}^{\mathrm{G}}$-nitro-L-arginine methyl ester (LNAME). They concluded that chronic NOS blockade does not alter insulin secretion.

The purpose of the present investigation was to study the activity of cNOS in Langerhans islets from control and diabetic rats in order to determine a probable relationship between islet integrity and activity of the enzyme, as well as a possible role of this enzyme in the regulation of blood glucose levels through modulation of insulin secretion by ß-cells.

\section{Material and Methods}

Animals

Assays were conducted on male Wistar rats weighing about 180-200 g. Rat glycemia levels were measured by an enzymatic method using a kit from Wiener Laboratories, Rosario, Argentina. One group of rats was injected intraperitoneally twice with streptozotocin (STZ) $(60 \mathrm{mg} / \mathrm{kg}$ body weight) in $20 \mathrm{mM}$ citrate buffer, $\mathrm{pH} 4.5$, with an interval of 7 days between injections. Blood glucose levels were determined before the first injection and one, two and three weeks after the last injection of STZ. Rats with no diabetic symptoms at the time of the last glycemia determination were excluded from the study. Blood glucose levels were also determined in control rats at 0 time and before sacrifice.

Isolation of Langerhans islets

Langerhans islets were isolated accord- 
ing to Lacy and Kostianovsky (14). Rats were anesthetized with a $10 \%$ ethyl urethane injection, their common bile duct was cannulated and the pancreas was perfused with $10 \mathrm{ml}$ of Hanks solution. The pancreas was removed and digested by incubation with type V collagenase (Sigma Chemical Co., St. Louis, MO) in Hanks solution for 20 min at $37^{\circ} \mathrm{C}$ and the digested material was diluted and centrifuged twice at $250 \mathrm{rpm}$ for $1 \mathrm{~min}$. The pellet was then added to a gradient containing 1.4, 1.6, 1.7 and $1.8 \mathrm{M}$ sucrose and centrifuged for $15 \mathrm{~min}$ at $2,500 \mathrm{rpm}$. Islets were found preferentially at the $1.6 / 1.7$ interface. The viability of islets from that fraction was determined by Trypan blue exclusion.

cNOS activity

cNOS activity was determined in pancreas homogenates and isolated Langerhans islets according to the method of Bredt and Snyder (15). Samples were homogenized in $20 \mathrm{mM}$ HEPES buffer containing $0.32 \mathrm{M}$ sucrose, $0.5 \mathrm{mM}$ EGTA and $1 \mathrm{mM}$ dithiotreitol, $\mathrm{pH}$ 7.2, and centrifuged at 10,000 rpm for $15 \mathrm{~min}$. Supernatants were added to cation exchange columns (AG 50WX-8) in the sodium form to remove endogenous arginine. Eluates were incubated in the same buffer in the presence of $2 \mathrm{mM} \mathrm{NADPH}$, $0.45 \mathrm{mM} \mathrm{CaCl}_{2}, 200 \mu \mathrm{M}$ arginine and $2 \mu \mathrm{Ci} /$ $\mathrm{ml}\left[{ }^{3} \mathrm{H}\right]$ arginine in a final volume of $0.25 \mathrm{ml}$ for $45 \mathrm{~min}$ at $37^{\circ} \mathrm{C}$. The reaction was stopped by the addition of $2 \mathrm{ml}$ of a stop solution containing $20 \mathrm{mM}$ HEPES, $5 \mathrm{mM}$ arginine and 4 mM EDTA. $\left[{ }^{3} \mathrm{H}\right]$ citrulline was quantitated after separation from $\left[{ }^{3} \mathrm{H}\right]$ arginine by eluting samples from the cation exchange AG 50WX-8 columns with $2 \mathrm{ml}$ of water. Radioactivity was measured by liquid scintillation counting. Calcium dependency of the enzyme was studied by adjusting the cation free concentration with 0.5 mMEGTA. Later analyses were performed in the presence of $0.1 \mu \mathrm{M}$ free calcium. NOS activity for different substrate concentrations and the effect of aminoguanidine were studied after 15 min of incubation in order to decrease non-enzymatic hydrolysis, which was high after $45 \mathrm{~min}$ and would probably interfere with enzymatic hydrolysis at low substrate concentrations. To study the effect of 10 or $200 \mu \mathrm{M}$ aminoguanidine on enzyme activity, $1 \mu \mathrm{M}$ arginine was used as substrate.

Histological analysis

The pancreas of control and diabetic rats was fixated in Lillie's formalin and embedded in paraffin, and 5- $\mu \mathrm{m}$ slices were stained with hematoxylin-eosin (HE). Photomicrographs were taken at 10X and 40X.

Protein concentration measurements

Protein concentrations were determined by the method of Lowry et al. (16).

Statistical analysis

Analysis of variance (ANOVA) was used to determine the statistical significance of the results.

Results

Male Wistar rats injected twice with STZ $(60 \mathrm{mg} / \mathrm{kg}$ ) became diabetic 20 days after the last injection. Table 1 shows the glycemias

Table 1 - Blood glucose levels of control and STZ diabetic rats.

Plasma glucose levels were determined by an enzymatic method at 0 time $\left(t_{0}\right)$ and 21 days $\left(t_{21}\right)$ after the last injection of streptozotocin in STZ-treated animals. Data are reported as means \pm SD of duplicate samples for 7 rats per group and are expressed as mg glucose/dl plasma and \% increment. a $\mathrm{P}<0.0001$ between STZ-treated rat glycemias at $t_{0}$ and at $t_{21}$ and $b P<0.0001$ between control and $S T Z$ rat glycemias at $t_{21}$. All statistical comparisons were by ANOVA.

\begin{tabular}{lccrrr}
\hline Group & $\begin{array}{c}\text { Glycemia at to } \\
(\mathrm{mg} / \mathrm{dl})\end{array}$ & $\begin{array}{c}\text { Glycemia at } \mathrm{t}_{21} \\
(\mathrm{mg} / \mathrm{dl})\end{array}$ & \% Increment & Min. $\Delta$ & Max. $\Delta$ \\
\hline Control & $87.5 \pm 18.5$ & $92.3 \pm 21.3$ & $8.4 \pm 27.5$ & -41.7 & 38.2 \\
STZ & $91.7 \pm 18.7$ & $339.6 \pm 107.3 \mathrm{a}, \mathrm{b}$ & $282.1 \pm 126.2$ & 103.2 & 479.5
\end{tabular}


of both control and STZ-treated animals obtained at 0 time and on the day of NOS activity determination.

Protein concentration- and calcium-dependencies of the enzyme activity in isolated Langerhans islets were determined in control rats. Langerhans islet NOS activity was linear for protein concentrations from 0 to $150 \mu \mathrm{g}$ (Figure 1) and decreased at higher

Figure 1 - Langerhans islet NOS activity from control rats measured at different protein concentrations in the samples. Three independent experiments were performed. Results are reported as means \pm SD of duplicate or triplicate samples and are expressed as nmol $10^{-4}$ of $\left[{ }^{3} \mathrm{H}\right] \mathrm{ci}-$ trulline formed during 45 min of incubation. Radioactivity was measured after $\left[{ }^{3} \mathrm{H}\right]$ citrulline separation from $\left[{ }^{3} \mathrm{H}\right]$ arginine on a cation exchange column. NOS activity was linear up to $150 \mu \mathrm{g}$ protein.

Figure 2 - Calcium dependency of Langerhans islet cNOS activity from control rats. Free calcium concentrations were adjusted with 0.5 M EGTA. Results are reported as means $\pm S D$ of triplicate samples from two independent experiments and represent specific activity of the enzyme expressed as nmol $10^{-4}$ of $\left.{ }^{3} \mathrm{H}\right]$ citrulline formed per $\mathrm{mg}$ protein during $45 \mathrm{~min}$ of incubation.

Figure 3 - Langerhans islet specific NOS activity from control rats measured at different substrate concentrations. Results are reported as means $\pm S D$ of triplicate samples for two independent experiments and represent specific activity of the enzyme expressed as nmol $10^{-4}$ of $\left[{ }^{3} \mathrm{H}\right]$ citrulline formed per $\mathrm{mg}$ of protein during 15 min of incubation.
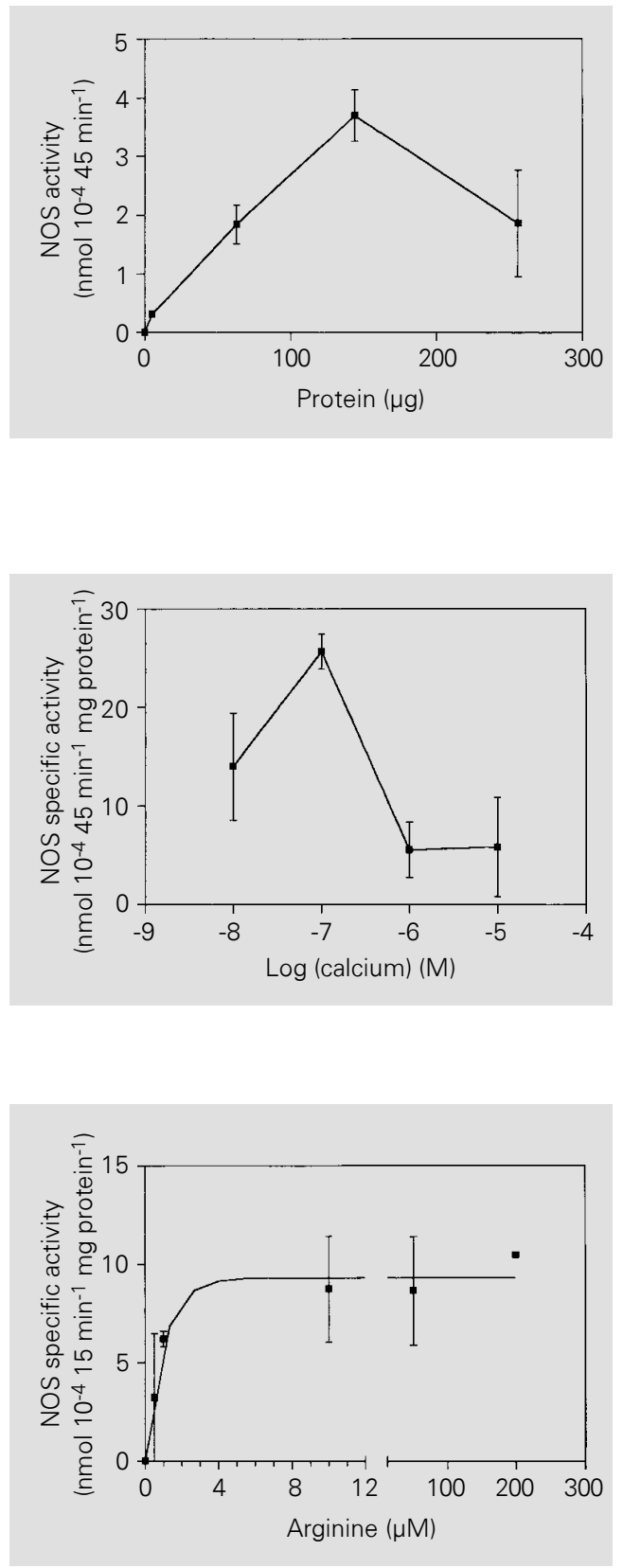

protein concentrations. This result may be the consequence of a parallel increase in the content of other enzymes in the samples such as arginase, which is active on mouse Langerhans islets (data not shown) or proteases. The results of calcium dependency are shown in Figure 2. NOS activity was optimal at $0.1 \mu \mathrm{M}$ calcium, decreasing at 10 $\mathrm{nM}, 1 \mu \mathrm{M}$ and $10 \mu \mathrm{M}$ calcium concentration. NOS activity was demonstrable in the presence of EGTA without calcium addition (data not shown). Since the optimal NOS activity was $0.1 \mu \mathrm{M}$ calcium, this was the calcium concentration used in further analyses. Figure 3 shows NOS activity for different substrate concentrations measured after 15 min of incubation. The concentration of substrate selected for subsequent analysis was $1 \mu \mathrm{M}$ arginine.

A comparison of NOS activity in total pancreas homogenate and isolated Langerhans islets between control and diabetic rats is shown in Figure 4. In control animals NO production was greatly increased in isolated islets when compared to total pancreas homogenate $(\mathrm{P}<0.0068)$. In contrast, the activity in diabetic isolated islets remained unchanged when compared to that found in total pancreas homogenate from the same group of animals. Diabetic rats exhibited lower NOS activity than controls for both total pancreas homogenates $(\mathrm{P}<0.02)$ and isolated Langerhans islets $(\mathrm{P}<0.001)$.

Aminoguanidine is reported to inhibit preferentially iNOS from different tissues (17). Corbett et al. (4) described aminoguanidine-mediated inhibition of IL-1ß-induced nitrite formation by Rin-m5F cells in vitro, in parallel with arterial blood pressure increases as the consequence of intravenous injection of aminoguanidine in rats. We studied the effect in vitro of aminoguanidine on Langerhans islets NOS activity from control and diabetic rats, in order to determine whether the activity measured in STZ-treated animals corresponded to a constitutive enzyme or to both constitutive and inducible 
enzymes. Ten $\mu \mathrm{M}$ and $200 \mu \mathrm{M}$ aminoguanidine did not inhibit NOS activity in control nor in diabetic rat Langerhans islets, when activity was determined in the presence of 1 $\mu \mathrm{M}$ of arginine (Figure 5).

The histological results for the pancreas of control and diabetic rats are illustrated in Figure 6 . The number and size of islets were dramatically reduced in STZ-treated animals (Figure 6B). Leukocyte infiltration can also be observed in tissues from diabetic pancreas (Figure 6D), thus suggesting an inflammatory process in these organs. Preliminary studies performed in our laboratory with STZ-injected prediabetic rats showed that the pancreas obtained from these animals and from diabetic rats exhibited few and small islets (probably containing a small proportion of $\beta$-cells) when compared to control. The only difference found between groups was blood glucose level and total NOS activity $\left( \pm \mathrm{Ca}^{2+}\right)$ which were lower in diabetic rats than in prediabetic rats (data not shown).

\section{Discussion}

Streptozotocin has been extensively used to produce type I diabetes in animals $(18,19)$. In mice, STZ-induced IDDM is probably mediated by iNOS induction in pancreatic islets and leukocytes (1). The pancreas of STZ-treated mice is characterized by lymphocyte and macrophage infiltration and islet necrosis. $\mathrm{N}^{\mathrm{G}}$-monomethyl L-arginine (NMMA), a well-known NOS inhibitor, prevents the development of diabetes in this animal model (20). Recently NO has been directly implicated in islet destruction. It is also probable that STZ acts as a donor of NO in a process analogous to that of $\mathrm{NO}$ donor compounds, since it contains a nitroso moiety that can release the effector molecule during decomposition (1). Turk et al. (21) and Kwon et al. (22) demonstrated that NO can be released from STZ. STZ-induced inhibition of insulin secretion and accumula-

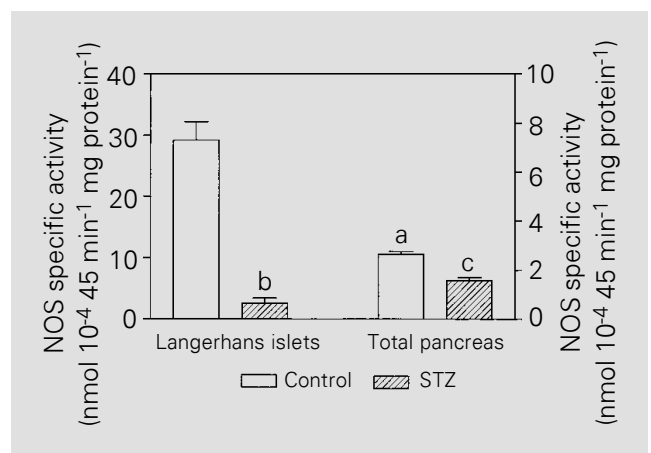

tion of cGMP by rat islets were reported by Turk et al. (21).

We decided to investigate cNOS activity in the pancreas of the rat as well as a possible relationship between the production of $\mathrm{NO}$ by this enzyme and the diabetes caused by streptozotocin treatment. The activity of Langerhans islet NOS that we measured in control rats corresponds to a constitutive isoform, in agreement with Kleemann and co-workers (23) who reported that iNOS mRNA could not be demonstrated in normal Wistar rats. We confirmed that our animals were in normal conditions, since they did not develop spontaneous diabetes (Table 1). According to the time-dependent induction of iNOS described by Niemann et al. (24) which became apparent $6 \mathrm{~h}$ after IL-1 treatment of insulin-producing cells and decreased after this time, the activity of the enzyme may not be detected long after STZ treatment of the rats. Niemann et al. (24) also reported that they observed a decrease in the transcription of iNOS under their experimental conditions, which seems to be due to a negative feedback induced by NO.

In preliminary studies, we detected NOS activity in the absence of calcium in the Langerhans islets of prediabetic but not of diabetic rats (data not shown). This activity may probably correspond to iNOS and yielded higher $\left[{ }^{3} \mathrm{H}\right]$ citrulline formation than cNOS in those samples. We confirmed that the enzyme activity we measured under our working conditions corresponded only to a constitutive one in control and diabetic rats,
Figure 4 - Specific activity of NOS measured in total pancreas homogenate and isolated Langerhans islets from control (open bars) and STZ diabetic rats (striped bars). Results are reported as means \pm SD from three independent experiments and are expressed as nmol $10^{-4}$ of $\left[{ }^{3} \mathrm{H}\right]$ citrulline formed per $\mathrm{mg}$ of protein during $45 \mathrm{~min}$ of incubation. a) $P<0.0068$ between Langerhans islet and total pancreas homogenate activities from control rats, b) $\mathrm{P}<0.001$ between control and STZ Langerhans islet activities and c) $\mathrm{P}<0.02$ between control and STZ total pancreas homogenate activities. All statistical comparisons were by ANOVA. 
since aminoguanidine addition to the reaction mixtures did not inhibit the activity in Langerhans islets isolated from both control and STZ diabetic rats (Figure 5).

Histological analysis of pancreas from control rats showed a normal number of Langerhans islets, in contrast to the small numbers found in STZ diabetic rats, whose blood glucose levels were $103 \%$ to $479 \%$ higher than those detected before STZ injection. Langerhans islets from the latter group were smaller than control ones and presented edema and leukocyte infiltration, as detected by their deeply staining borders. Other ex-

Figure 5 - The effect of two different concentrations of aminoguanidine on Langerhans islet NOS specific activity from control (open bars) and STZ (striped bars) diabetic rats. Results from two independent experiments are reported as mentioned in Figure 3. a) $\mathrm{P}<0.005$ between control and STZ Langerhans islet activities when aminoguanidine was not added to the reaction mixtures (ANOVA)

Figure 6 - Histology from control and STZ diabetic rat pancreas. Slices of $5 \mu \mathrm{m}$ were stained with hematoxylin-eosin and photomicrographs were taken at $10 X(A$, control and $\mathrm{B}, \mathrm{STZ}$ ) as well as 40X (C, control and D, STZ).

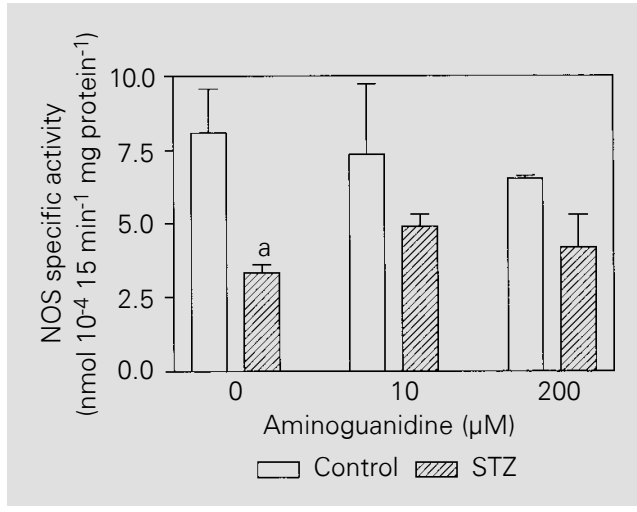

periments should be performed to elucidate if the inflammatory process indicated by leukocyte infiltration is the result of an autoimmune response or corresponds to marginal infiltration as the consequence of a direct toxic effect of STZ

cNOS activity was two- to ten-fold higher in Langerhans islets than in total pancreas homogenates from control rats, depending on the time of sample incubation (Figures 4 and 5). On the other hand, diabetic rats did not show enhanced enzyme activity in isolated Langerhans islets, in agreement with the characteristics of islets from treated rats described above. NOS specific activity in STZ diabetic rats was significantly lower than in control animals both in pancreas homogenates and in isolated Langerhans islets.

According to our results, hyperglycemia in STZ diabetic rats may be caused by reduced insulin secretion, mediated at least in part by a decrease in cNOS activity. NO release by iNOS should be a brief response of the cells to injury at the beginning of the treatment, but is not elevated after the onset of hyperglycemia in STZ-treated animals.

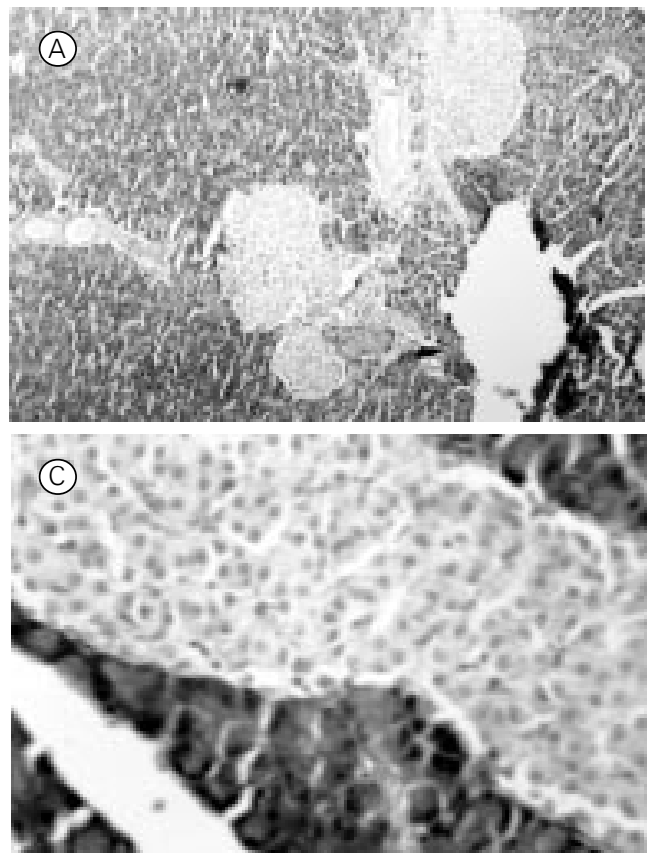


The mechanism of action of STZ that produces diabetic lesions of Langerhans islets may also involve an impairment of insulin secretion as reported by Turk et al. (21).

Independent of the mechanism of action of STZ that produces Langerhans islet destruction, severe damage to $\beta$-cells must be responsible for the alterations in cNOS activity observed here in STZ diabetic rats. Judging from our preliminary results on histology, glycemia and cNOS activity in prediabetic rats, the amount of NO produced in Langerhans islets seems to be crucial in the regulation of insulin secretion by STZ-treated rat $\beta$-cells.

We are not able to establish if the mechanism that modulates insulin release is autocrine (9) or paracrine or whether it corresponds to nNOS or eNOS isoforms. Burrell et al. (25) found co-localization of nNOS and somatostatin in human pancreatic islets and postulated that NO-mediated insulin re- lease may occur through a paracrine mechanism from nearby somatostatin-producing cells rather than through an autocrine mechanism. Preliminary studies (Fonovich de Schroeder TM and Catanzaro OL, unpublished data) allow us to suggest that the activity of NOS we measured may probably correspond to an eNOS isoform since it was activated by bradykinin in vitro (26).

Our findings permit us to suggest that low levels of NO may be necessary for positive modulation of insulin secretion, although immunohistochemistry should be performed to evaluate the proportion of $\beta$-cells and somatostatin-producing cells in the Langerhans islets of STZ-treated rats and the colocalization of enzyme activity. These experiments would be useful to establish the source of NO and the exact correlation between impairment in cNOS activity and proportion of NO-producing cells in damaged islets.

\section{References}

1. Corbett JA, Kwon G, Hill JR \& McDaniel $M L$ (1995). Role of nitric oxide in islet Bcell destruction associated with the development of autoimmune diabetes. Diabetes Annual, 9: 265-294

2. Eizirik DL, Flodström $M$, Karlsen $A E$ \& Welsh N (1996). The harmony of the spheres: inducible nitric oxide synthase and related genes in pancreatic beta cells. Diabetologia, 39: 875-890.

3. Flodström M, Welsh N \& Eizirik DL (1996). Cytokines activate the nuclear factor $\kappa \mathrm{B}(\mathrm{NF}-\mathrm{\kappa B})$ and induce nitric oxide production in human pancreatic islets. FEBS Letters, 385: 4-6.

4. Corbett JA \& McDaniel ML (1992). Does nitric oxide mediate autoimmune destruction of ß-cells? Diabetes, 41: 897-903.

5. Rabinovitch A, Suarez-Pinzon WL, Sorensen O \& Bleackley RC (1996). Inducible nitric oxide synthase (iNOS) in pancreatic islets of nonobese diabetic mice: Identification of iNOS-expressing cells and relationships to cytokines expressed in the islets. Endocrinology, 137: 2093-2099.

6. Eizirik DL, Delaney CA, Green MHL, Cunningham JM, Thorpe JR, Pipeleers
DG, Hellerström C \& Green IC (1996). Nitric oxide donors decrease the function and survival of human pancreatic islets. Molecular and Cellular Endocrinology, 118: 71-83.

7. Stamler JS (1994). Redox signalling: Nitrosylation and related target interactions of nitric oxide. Cell, 78: 931-936.

8. Guerrero JM, Reiter RJ, Poeggeler B, Chen L-D \& Tan D-X (1994). Elevation of cyclic GMP levels in the rat pineal gland induced by nitric oxide. Journal of Pineal Research, 16: 210-214.

9. Schmidt HHHW, Warner TD, Ishii K, Sheng H \& Murad F (1992). Insulin secretion from pancreatic $B$ cells caused by Larginine-derived nitrogen oxides. Science, 255: 721-723.

10. Laffranchi R, Gogvadze V, Richter C \& Spinas GA (1995). Nitric oxide (nitrogen monoxide, NO) stimulates insulin secretion by inducing calcium release from mitochondria. Biochemical and Biophysical Research Communications, 217: 584-591.

11. Panagiotidis G, Åkesson B, Rydell EL \& Lundquist I (1995). Influence of nitric oxide synthase inhibition, nitric oxide and hydroperoxide on insulin release induced by various secretagogues. British Journal of Pharmacology, 114: 289-296.

12. Jones PM, Persaud SJ, Bjaaland T, Pearson JD \& Howell SL (1992). Nitric oxide is not involved in the initiation of insulin secretion from rat islets of Langerhans. Diabetologia, 35: 1020-1027.

13. Pueyo ME, Gonzalez W, Pussard E \& Arnal JF (1994). Insulin secretion in rats with chronic nitric oxide synthase blockade. Diabetologia, 37: 879-884.

14. Lacy PE \& Kostianovsky M (1967). Method for the isolation of intact islets of Langerhans from the rat pancreas. Diabetes, 16: 35-39.

15. Bredt DS \& Snyder SH (1989). Nitric oxide mediates glutamate-linked enhancement of cGMP levels in the cerebellum. Proceedings of the National Academy of Sciences, USA, 86: 9030-9033.

16. Lowry $\mathrm{OH}$, Rosebrough $\mathrm{NJ}$, Farr AL \& Randall RS (1951). Protein measurement with the Folin phenol reagent. Journal of Biological Chemistry, 193: 265-275.

17. Eizirik DL \& Leijerstam F (1994). The inducible form of nitric oxide synthase (iNOS) in insulin-producing cells. Diabete et Metabolisme, 20: 116-122. 
18. Zuccollo A, Navarro M, Prendes GM, Dominguez A \& Catanzaro OL (1996). Effects of HOE 140 on some renal functions in type I diabetic mice. Archives of Physiology and Biochemistry, 104: 252-254.

19. Kolb-Bachofen V, Epstein S, Kiesel J \& Kolb H (1988). Low dose streptozotocininduced diabetes in mice. Electron microscopy reveals single cell insulitis before diabetes onset. Diabetes, 37: 21-27.

20. Kolb H, Kiesel U, Kröncke K-D \& KolbBachofen V (1991). Suppression of low dose streptozotocin induced diabetes in mice by administration of a nitric oxide synthase inhibitor. Life Sciences, 49: 213217.

21. Turk J, Corbett JA, Ramanadham S, Bohrer A \& McDaniel ML (1993). Bio- chemical evidence for nitric oxide formation from streptozotocin in isolated pancreatic islets. Biochemical and Biophysical Research Communications, 197: 14581464.

22. Kwon NS, Lee SH, Choi CS, Kho T \& Lee HS (1994). Nitric oxide generation from streptozotocin. FASEB Journal, 8: 529533.

23. Kleemann R, Rothe H, Kolb-Bachofen $\mathrm{V}$, Xie OW, Nathan C, Martin S \& Kolb H (1993). Transcription and translation of inducible nitric oxide synthase in the pancreas of prediabetic BB rats. FEBS Letters, 328: 9-12.

24. Niemann A, Björklund A \& Eizirik DL (1994). Studies on the molecular regulation of the inducible form of nitric oxide synthase (iNOS) in insulin-producing cells. Molecular and Cellular Endocrinology, 106: 151-155

25. Burrell MA, Montuenga LM, García M \& Villaro AC (1996). Detection of nitric oxide synthase (NOS) in somatostatin-producing cells of human and murine stomach and pancreas. Journal of Histochemistry and Cytochemistry, 44: 339-346.

26. Moncada $S$, Palmer RMJ \& Higgs $A$ (1992). El descubrimiento y el significado biológico de la vía metabólica L-arginina: Oxido nítrico. In: I Encuentro Internacional sobre Hipertensión y Arterioesclerosis celebrado en La Coruña, España. Chapter 1: 3-30. 1st edn. Edicomplet, Madrid, España. 